\title{
A Rare Case of Chronic Suppurative Appendicitis in Neonatal Presenting as Intestinal Malrotation
}

Putu Pradnyanita Mustika ${ }^{1 *}$, Made Sukmawati ${ }^{1}$, I. Made Darmajaya ${ }^{2}$, I. G. A. Sri Mahendra Dewi ${ }^{3}$, I. Wayan Dharma Artana ${ }^{1}$, Made Kardana ${ }^{1}$, Putu Junara Putra ${ }^{1}$, Kadek Deddy Ariyanta ${ }^{2}$

${ }^{1}$ Department of Child Health, Faculty of Medicine, Udayana University, Sanglah General Hospital, Denpasar, Bali, Indonesia ${ }^{2}$ Department of Pediatric Surgery, Faculty of Medicine, Udayana University, Sanglah General Hospital, Denpasar, Bali, Indonesia; ${ }^{3}$ Department of Pathology-Anatomy, Faculty of Medicine, Udayana University, Sanglah General Hospital, Denpasar, Bali, Indonesia

Edited by: Ksenija Bogoeva-Kostovska Citation: Mustika PP, Sukmawati M, Darmajaya IM, Dew IG, Artana IW, Kardana M, Putra PJ, Ariyanta KD. A Rare Case of Chronic Suppurative Appendicitis in Neonata Presenting as Intestinal Malrotation. Open Access Mace J Med Sci. 2021 Sep 17; 9(C):158-162. https://doi.org/10.3889/oamjms.2021.6613 Keywords: Neonatal appendicitis; Intestinal malrotation; *Correspondence: Putu Pradnyans procedure Department of Child Health. Faculty of Medicine Udayan University/Sanglah Hospital, Diponegoro Road, Denpasar, Bali, Indonesia. E-mail: pradnyamustika@gmail.com Received: 12-Jun-2021 Revised: 25-Aug-202 Accepted: 07-Sep-2021

Copyright: ๑ 2021 Putu Pradnyanita Mustika, Made Sukmawati, I. Made Darmajaya, I. G. A. Sri Mahendra Dewi, I. Wayan Dharma Artana, ade Kardana, Putu Junara Putra, Kadek Deddy Ariyant any financia Competing Interests: The authors have declared that no Open Access: This is an open-access article distributed under the terms of the Creative Commons AttributionNonCommercial 4.0 International License (CC BY-NC 4.0)

\begin{abstract}
Neonatal appendicitis (NA) is an extremely rare acute abdomen condition, moreover, if it is a chronic suppurative one. The definite risk factor of NA is barely unknown. The signs and symptoms are often nonspecific and appear after perforation occurs. Most of the cases were found unexpectedly during surgery suspected as other diagnoses. A 7-day-old male neonate presenting lethargic and hypoglycemia since $1^{\text {st }}$ day of life. Patient drunk breast milk right after since he was born. Meconium was produced $<24 \mathrm{~h}$. On the $3^{\text {rd }}$ day of hospitalization, he experienced bilious vomiting and abdominal distension, so nasogastric tube was installed. Physical examination revealed decreased bowel sound. Investigation showed leucocytosis, slightly increased procalcitonin and abdominal X-ray showed that gas distribution lasted until third part of duodenum followed by minimal gas distribution in the distal part of duodenum The patient was suspected as distal duodenum stenosis or proximal jejunum. Intraoperatively, it was found that there was second part duodenum malrotation and open Ladd's procedure was done. During Ladd's procedure, a perforated appendix was also found. The histopathology result revealed that it was a chronic suppurative appendicitis. Patient was discharged in good condition 20 days after surgery. NA is a rare condition with nonspecific signs and symptoms which was usually found accidentally during surgery suspected as other diagnoses.
\end{abstract}

\section{Introduction}

Neonatal appendicitis (NA) is an extremely rare acute abdomen condition. Although it is commonly happened in children, the incidence decreases in infant $<2$ years old and become extremely rare in the neonatal period. NA incidence is accounted for approximately $0.04-0.2 \%$ of childhood appendicitis. Male and preterm neonates are often affected [1], [2]. The pathophysiology of NA is different compared to elder children. The definite risk factor of NA is barely unknown and it is usually presented with any other symptoms. In elder children, appendicitis is usually caused by luminal obstruction. Recumbent positions, funnel-shaped appendix of neonates, and milk are protection against obstruction. Infective agents such as adenoviruses which are known can lead to lymphoid hyperplasia are least likely in newborn babies as they have lesser possibility of having intestinal and respiratory infection. Therefore, it is rare for neonates to get appendicitis [2], [3].
The signs and symptoms are often nonspecific and appear later after appendix perforation happens. This is causing general peritonitis and intestinal congestion mimicking sepsis. Thus, it is more difficult to get precisely preoperative diagnose, subsequently giving a delay and complications. Most of the previous NA cases were found accidentally during routine examinations or investigations or encountered during surgery suspected as other diagnoses [4]. This induced NA having a high mortality rate nowadays, as high as $34 \%$ especially in perforated cases [1].

Unlike in elder children, leukocyte count is inaccurate at diagnosing NA. Imaging is not always susceptible. Ultrasonography (USG) is useful but not always conclusive for appendicitis. Plain radiograph, although is not the gold standard for diagnosing appendicitis, is helpful in detecting complications [5]. Histopathology examination enables us to confirm the diagnose. Resection is the sole treatment with an excellent outcome [1]. 


\section{Case Report}

A 2-day-old male neonate was brought to Sanglah Hospital's emergency room (ER). Patient was referred from private hospital with neonatal hypoglycemia and leukocytosis. Patient had a history of repeated low blood sugar since birth. Patient looked lethargic and reluctant to drink with poor sucking reflexes since day 1 after birth. Meconium was produced $<24 \mathrm{~h}$ since birth. When arrived at Sanglah Hospital, the patient looked icteric. There was no history of abnormal temperature.

Patient was a second-born child. There was no abnormality during pregnancy and prenatal ultrasound examination. There was no history of hyperglycemia pregnancy and no risk factor for developing neonatal sepsis during delivery were found. He was delivered through cesarean section because of severe preeclampsia and locus minoris resistentiae. He was born vigorously, his weight was $2090 \mathrm{~g}$ and term.

Physical examination showed the head was in normal shape and major fontanel was flat. There were no sunken eyes and conjunctiva injection, but the sclera was found icteric. Pupils light reflect was normal. No nasal flare was found. It was no lymph nodes enlargement on the neck. The chest was symmetrical both when resting and movement. Breath sound was vesicular without rales or wheezing, the first and second heart sounds were normal, regular, and no murmur in auscultation. There was no lymph nodes enlargement found on both axilla. No sign of abdominal distension. Bowel sound was normal when auscultated. Anal and genital examination was normal.

Laboratory result revealed that the leukocyte count was $33.21 \times 10^{3} / \mu \mathrm{L}$, dominated by lymphocyte $(54.8 \%)$ and IT ratio was 0.17 . Serum blood sugar was $2 \mathrm{mg} / \mathrm{dL}$. Total bilirubin was $11.02 \mathrm{mg} / \mathrm{dL}$ with direct bilirubin was $0.90 \mathrm{mg} / \mathrm{dL}$. Procalcitonin was $2.57 \mathrm{mg} / \mathrm{dL}$. Patient was diagnosed as full-term baby, low birth weight $(2090 \mathrm{~g})$, small for gestational age, neonatal hypoglycemia, suspected as early-onset neonatal sepsis. Patient was given oral trophic feeding and parenteral nutrition with glucose infusion rate was eight $\mathrm{mg} / \mathrm{kg} / \mathrm{min}$. He was also treated with first-line antibiotic (ampicillin and amikacin) and phototherapy.

On the $3^{\text {rd }}$ day of treatment (4 days old), patients were obtained with complaints of bilious vomiting. Patient also vomited milk not long after he drunk. The previous complaint of lethargy and repeated hypoglycemia was not getting better. Since his first meconium, there was no more feces produced afterward. On physical examination, abdominal distension was found with decreased bowel sound (Figure 1). From abdominal X-ray, it was found that gas distribution lasted until the third part of the duodenum with minimal gas at the distal part of the duodenum (Figure 2). The patient was suspected as distal duodenum stenosis or proximal jejunum.
Based on the clinical and adjunctive examination, the patient was diagnosed as full-term baby, low birth weight $(2090 \mathrm{~g})$, small for gestational age, observation of abdominal distension caused by obstruction suspected as second part duodenum malrotation, persistent hypoglycemia, suspected as early-onset neonatal sepsis. Since his $1^{\text {st }}$ day admission, no clinical septic shock was found. Patient was continuously treated with antibiotic (ampicillin, gentamicin), temporaryfasting, given parenteral nutrition, and nasogastric tube for abdominal decompression. As for hypoglycemia, high glucose infusion was already given since day 1 at hospital but no improvement was found. Intravenous hydrocortisone was then decided to be given for three consecutive days. While patient was also prepared for Ladd's procedure to encounter the intestinal malrotation.

Surgical procedure was done on the $7^{\text {th }}$ day of hospitalization (8 days old). During open Ladd's procedure, the surgeon found malrotation and grade 2 adhesion between the colon and gall bladder (Figure 3a). After releasing the malrotation and adhesion, when the inversion-ligation appendectomy was about to be performed, perforated appendix was found (Figure 3b). Conventional appendectomy was performed and the removed appendix was sent for histopathology examination. The result was chronic suppurative appendicitis and abscess (Figure 4).

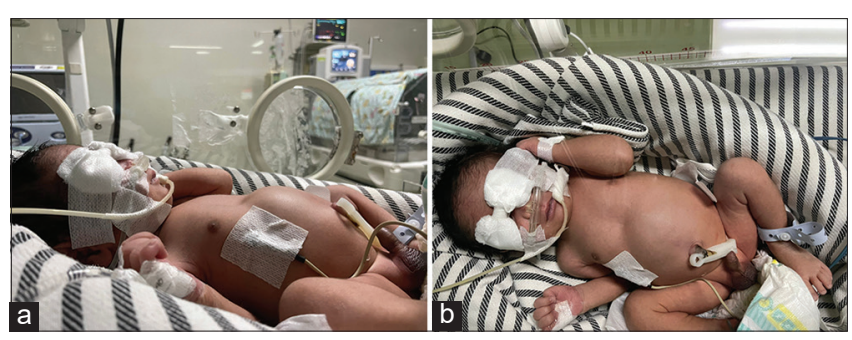

Figure 1: ( $a$ and b)Clinical presentation of the patient on the third day of admission. Patient was having abdominal distension.

Patient was sent to neonatal intensive care unit right after surgery. The patient was given intravenous antibiotics such as ampicillin, gentamicin, metronidazole, and total parenteral nutrition. Three days after surgery,

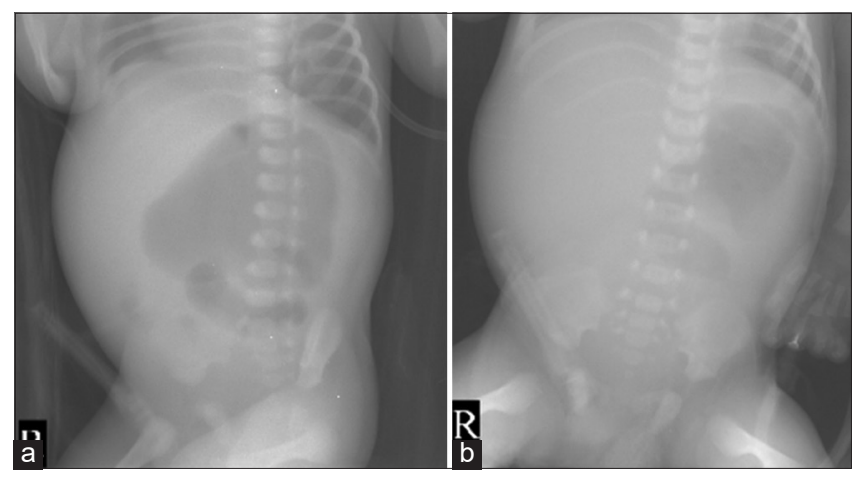

Figure 2: Abdominal X-ray result showed gas distribution before (a) and after (b) nasogastric tube insertion. Intestinal gas decreased in gaster after nasogastric tube insertion with minimal gas distribution in the caudal segment of third part duodenum 


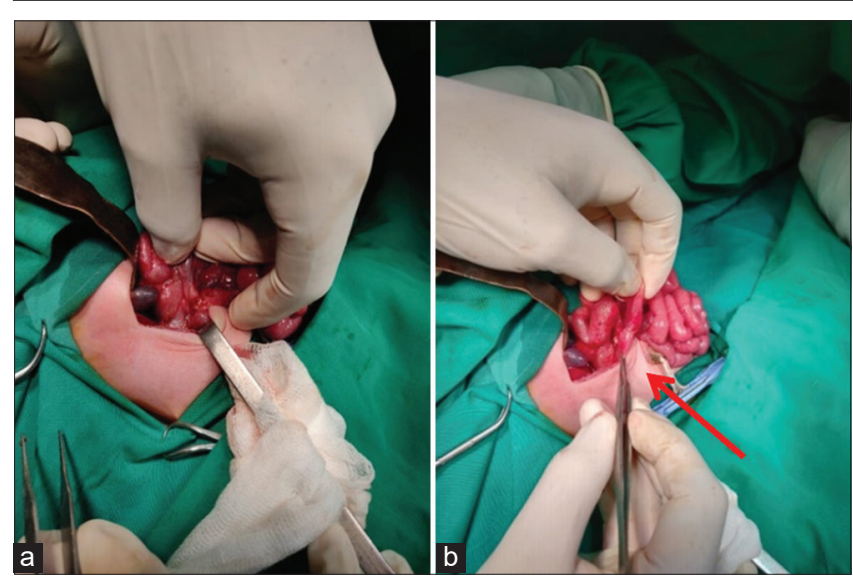

Figure 3: Surgical finding during surgery. (a) Intestinal malrotation and grade 2 adhesion between colon and gallbladder, (b) Perforated appendix

tropic feeding through feeding tube was started. On the day $8^{\text {th }}$ of surgery, the patient was referred to the neonatal ward and the hypoglycemia was improved. Full fed was reached on the $11^{\text {th }}$ day after surgery. Blood culture, taken on the $1^{\text {st }}$ day admission before antibiotic was given, revealed no bacterial growth, so a suspicion of sepsis could be resolved. Twenty days after surgery, the patient was discharged in good condition.

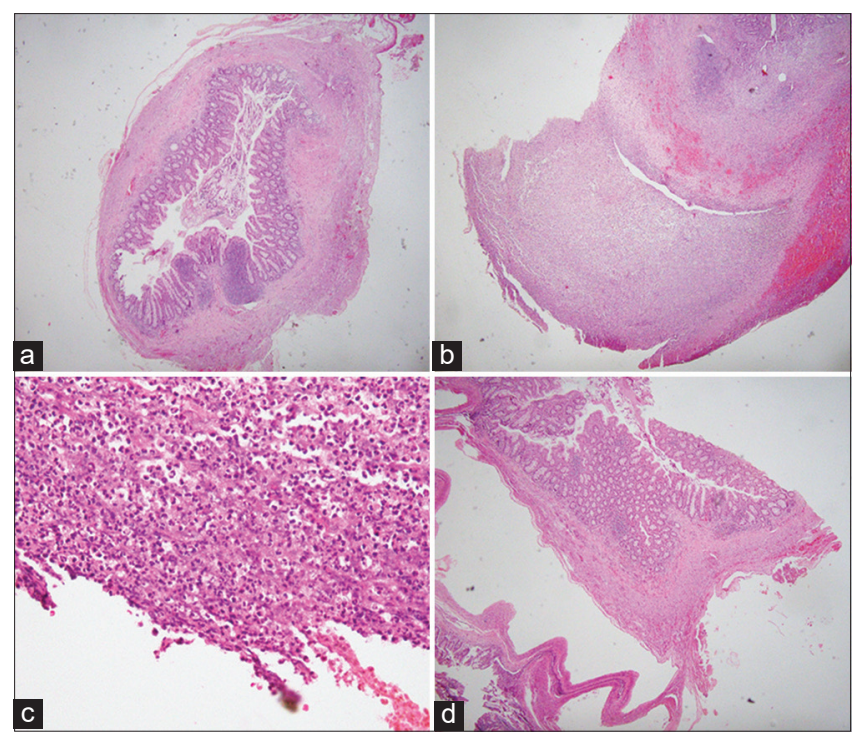

Figure 4: (a) Middle layer of appendix consisted of mucosal, submucosal muscularis, and serous layers, (b) Discontinuity of the serous layer tissue with inflammatory cells in the form of PMN neutrophil and lymphoplasmacytic at the distal appendix, (c) PMN neutrophil and lymphoplasmacytic in subserous layer, (d) Proximal appendix with vasodilated vessels at serous layer

\section{Discussion}

Acute appendicitis is highly infrequent in the neonatal period. Although it is commonly happened in pediatric patients, fewer than 50 cases during the past 30 years have been reported for neonates around the world. It is rarely considered as a differential diagnosis of acute abdomen in neonates. A review of the literature showed male was predominance with estimated ratio 3 to 1 which remained unexplained [1], [2]. NA has been reported in infants from the $1^{\text {st }}$ day of life, there were even cases in prenatal debut. Traditionally, preterm neonates are considered to be more vulnerable to NA due to immature immune systems and limited physiological reserve. Recently, both preterm and term baby are equally affected [1], [3]. This patient was a term baby presenting abnormal clinical symptoms since 2 days old.

The exact etiology of NA remains unknown. It is different compared to appendicitis symptoms at any other times of life. Most of the cases were found with comorbidities such as cystic fibrosis, Hirschsprung disease, meconium plug, inguinal or umbilical hernia, chorioamnionitis, group A streptococcal sepsis and many more [3]. Different theories have been proposed to explain the possible pathogenesis of NA including the following [2], [3]:

1. Immune deficiency favored by situations or conditions such as prematurity, chorioamnionitis or early sepsis which could increase susceptibility to infectious disease.

2. Condition causing vascular insufficiency or producing low blood flow such as perinatal asphyxia, hypoxia, heart disease, extracorporeal membrane oxygenation dependence which could favor appendix perforation.

3. Underlying disease that could lead to caecum obstruction. The obstruction later can cause bacterial overgrowth, elevated intraluminal pressure in the appendix and could lead to perforation.

No illnesses history during the pregnancy period were noted, nor history of consuming any traditional medicine. There was no abnormality during pregnancy or delivery reported. The intestinal malrotation, in this case, suggested as there was possibility of impaired blood flow in the peri-appendicular area which led to appendix perforation or possibly, malrotation and appendicitis were two different conditions that happened simultaneously. The perforated appendix was found accidentally while Ladd's surgery was done to encounter the intestinal malrotation.

Intestinal malrotation is a developmental anomaly affecting the position and peritoneal attachment of small and large bowels during organogenesis in the fetal period. It has been defined as absent or incomplete rotation and fixation of the embryonic gut around the superior mesenteric artery (SMA). The incidence of malrotation approximately 15 per 1 million in children $<1$ year old and 10 per 1 million in children 1-2 years old. Intestinal rotation occurs during the fourth until $12^{\text {th }}$ weeks of gestation. Normal gut rotation places the two ends of the intestinal tract, the proximal 
duodenojejunal loop, and the distal caecocolic loop, simultaneously in their proper positions. In this process, the developing primary mid-gut herniates into the base of the umbilical cord, returns, and becomes fixed, having as much as $270^{\circ}$ counter-clockwise rotation around the axis of the SMA. Intestinal rotation abnormalities can happen caused by perturbations in the sequence of herniation, rotation, and fixation of the midgut [6].

There is no specific clinical manifestation of NA. They can be presented as variate symptoms or found incidentally during surgery for any other diagnoses. The signs and symptoms were often found later when the perforation occurs which causes a general peritonitis or signs and symptoms related to the comorbidities [4]. A report by Raveenthiran, 2015, who reviewed 52 cases with NA, concluded that the usual symptoms were abdominal distension (89\%), vomiting (54\%), pneumoperitoneum (52\%), fever (31\%). Pneumoperitoneum was said to be the most useful sign but not always found in all cases. The patient might be having sepsis which was seen as abnormal temperature, lethargic, hypoglycemia, and bilious vomiting. Thus, it was difficult to do preoperative diagnose, subsequently led to a delay and complications causing higher possibility to mortality in NA as high as $34 \%$ [7]. Normally, the clinical manifestation of intestinal malrotation was abdominal pain dan bilious vomiting secondary to bowel obstruction. Confusingly, bilious vomiting is the most common symptom occurred among almost all other diseases in the neonatal period. Clinical features of NA in elder patients (infants or children) include chronic or recurrent colicky abdominal pain, intermittent constipation, solid food intolerance, abdominal distension, recurrent non-bilious vomiting, malabsorption/chronic diarrhea, failure to thrive, common bile duct obstruction, intestinal obstruction, gastrointestinal bleeding, peritonitis and even septic shock [6].

Due to these reasons, there was often a delay in diagnosing acute appendicitis in children and giving the exact surgery. In the past, the diagnose was made at autopsy in $60 \%$ of cases. Later on, almost all cases were diagnosed during surgery. Appendicitis with perforation was found in $80-85 \%$ of cases, thus increasing the severity of the symptoms [8]. The higher rate of perforation in the neonate is due to the fact that the appendix wall is very thin and has poor blood flow around it, the omentum is under developed and the abdominal cavity is relatively small, low cecum elasticity, and low resistance to infection. Afterward, perforation allows contamination occurred in the peritoneum [2]. On the $3^{\text {rd }}$ day in hospital, patient had an abdominal distension followed by bilious vomiting. Anand et al. reported that more likely the classical presentation of infant with intestinal malrotation are abdominal distension with bilious vomiting compared to elder children. It was probably due to the higher degree of duodenal obstruction and associated midgut volvulus than those adults that lesser to cause obstruction [9].

The preoperative diagnostic of NA is barely achieved. Once the patient has a sign and symptom of acute abdomen such as abdominal distension and vomiting, imaging or laboratory examination must be performed [2]. Usually, leukocytosis was found in patient with appendicitis. Sepsis screening such as C-reactive protein and blood culture was positive in only $27 \%$ of cases [1]. In this case, the procalcitonin slightly increased but blood culture was normal so sepsis could be resolved. It is recommended to undergo an abdominal X-ray or Doppler ultrasound after the physical examination because NA has an unpredictable and highly variable clinical presentation [5]. Abdominal radiograph may show abnormal gas pattern, free peritoneal fluid and air, thickened abdominal wall, a right scoliosis, and obliteration of psoas margin [10]. On abdominal USG, the presence of intra-abdominal abscess, absence of gas in appendix lumen, or evidence of fluid in right iliac fossa strongly suggests acute appendicitis [5]. Abdominal $X$-ray of this patient revealed gas distribution in the gastric and third part of the duodenum followed by minimal gas in the distal part of the duodenum. The patient was suspected as distal duodenum stenosis or proximal jejunum. Although abdominal USG particularly is one of the other investigations that should be done in such as suspected case like this, it was not done due to local guideline and restricted regulation of local health service management, abdominal X-ray was enough to support the diagnosis of stenosis at the beginning the patient was not suspected of having appendicitis.

Surgical intervention is necessarily be done in patient with any sign of peritonitis. Early laparoscopy or laparotomy should be undertaken to cure the NA with perforation by doing an appendectomy. Early management is needed to avoid high mortality rate. As for intestinal malrotation, the surgical intervention must be done due to any sign of acute abdomen presented [11] This patient already developed symptoms of abdominal distension and vomiting. Open Ladd's procedure was done to the patient, aiming to encounter the intestinal malrotation. The procedure involved counterclockwise detorsion of the bowel, surgical division of Ladd's bands, widening of the small intestine's mesentery artery, performing an appendectomy, and reorientating the small bowel on the right and the cecum and colon on the left. Appendectomy is performed with a purpose if in later life the inflammation of the appendix happens, it will not be confused by atypical presentation of appendicitis.

Laparoscopic approach of the Ladd's procedure is increasingly used along with the advanced of minimally invasive surgical techniques. This technique has some advantages and disadvantages. Benefit of doing laparoscopic surgery include better cosmetic secondary to smaller incisions, increased visualization, decreased risk of infection, and reduce 
length of stay. Potential disadvantages include difficulty with mobilization of the small bowel and decreased postoperative adhesion formation that theoretically put the patient at a greater risk of postoperative volvulus. Isani et al. concluded that no evidence can support laparoscopic is superior to open Ladd's procedure. Open surgery was associated with shorter operating times and fewer clinic visits. Furthermore, laparotomy remains as the most favored procedure for patients with volvulus [12].

Surgical procedure to treat intestinal malrotation emphasizes on early diagnosis and treatment to minimize the risk of volvulus. Once the procedure is safely performed, immediate complication after surgery such as poor feeding, bowel resection, and short gut syndrome following volvulus can be reduced. Patient is frequently discharged with a good condition. The Ladd's procedure intentionally creates intra-abdominal adhesions to maintain the de-rotated orientation of the intestine. Adhesions can result in small bowel obstruction at any point in the child's future life [13].

\section{Conclusion}

NA is an extremely rare acute abdomen condition. Diagnosing NA is often difficult for it could present as variate symptoms and is usually found incidentally during surgery for any other diagnoses. The signs and symptoms are often found later when the perforation occurs presenting as general peritonitis. Early recognition and appropriate management are crucial to avoid high mortality rate.

\section{Patient consent}

Consent to publish the case report was not obtained. This report does not contain any personal information that could lead to patient's identification.

\section{References}

1. Arias-Llorente RP, Flórez-Díez $P$, Oviedo-Gutiérrez M, SuárezRodríguez M, Costa-Romero M, Solís-Sánchez G, et al. Acute neonatal appendicitis: A diagnosis to consider in abdominal sepsis. J Neonatal Perinatal Med. 2014;7(3):241-6. https://doi. org/10.3233/npm-14814003

\section{PMid:25318628}

2. Raveenthiran V. Neonatal Appendicitis (Part 1): A Review of 52 cases with Abdominal Manifestation. J Neonatal Surg. 2015;4(1):4. https://doi.org/10.47338/jns.v4.157 PMid:26023528

3. Wang Y, Wu Y, Guan W, Yan W, Li Y, Fang J, et al. Meconium peritonitis due to fetal appendiceal perforation: Two case reports and a brief review of the literature. BMC Pediatr. 2018;18(1):162. https://doi.org/10.1186/s12887-018-1133-8 PMid:29751786

4. Khan R, Menon $P$, Rao KLN. Beware of neonatal appendicitis. J Indian Assoc Pediatr Surg. 2010;15(2):67-9. https://doi.org/10.4103/0971-9261.70646 PMid:20975787

5. Si SY, Guo YY, Mu JF, Yan CY. The sonographic features of neonatal appendicitis. Medicine (Baltimore). 2017;96(45):e8170. https://doi.org/10.1097/md.0000000000008170

PMid:29137008

6. Langer JC. Intestinal rotation abnormalities and midgut volvulus. Surg Clin North Am. 2017;97(1):147-59. https://doi. org/10.1016/j.suc.2016.08.011

PMid:27894424

7. Schwartz KL, Gilad E, Sigalet D, Yu W, Wong AL. Neonatal acute appendicitis: A proposed algorithm for timely diagnosis. J Pediatr Surg. 2011;46(11):2060-4. https://doi.org/10.1016/j. jpedsurg.2011.07.018 PMid:22075333

8. Secco IL, Costa T, de Moraes EL, de Freire MH, Danski MT, Cavalcante RP. Neonatal appendicitis: A survival case study. Rev Bras Enferm. 2017;70(6):1296-300. https://doi. org/10.1590/0034-7167-2016-0610

PMid:29160493

9. Anand U, Kumar R, Priyadarshi RN, Kumar B, Kumar S, Singh VP. Comparative study of intestinal malrotation in infant, children, and adult in a tertiary care center in India. Indian $\mathrm{J}$ Gastroenterol. 2018;37(6):545-9. https://doi.org/10.1007/ s12664-018-0914-1

PMid:30535747

10. Ayoub BH, Al Omran Y, Hassan A, Al Hindi S. The importance of timely detection and management in neonatal appendicitis. Case Reports. 2014;2014:bcr2014203663-bcr2014203663. https://doi.org/10.1136/bcr-2014-203663

PMid:24855077

11. Ferrero L, Ahmed $Y$ Ben, Philippe $P$, et al. Intestinal malrotation and volvulus in neonates: Laparoscopy versus open laparotomy. J Laparoendosc Adv Surg Tech A. 2017;27(3):318-21. https:// doi.org/10.1089/lap.2015.0544 PMid:28055334

12. Isani MA, Schlieve CR, Jackson J, Elizee MR, Kim ES. Is less more? Laparoscopic vs open ladd's procedure in children with malrotation. J Am Coll Surg. 2016;223(4):e156. https://doi. org/10.1016/j.jamcollsurg.2016.08.397 PMid:29937013

13. Murphy FL, Sparnon AL. Long-term complications following intestinal malrotation and the Ladd's procedure: A 15 year review. Pediatr Surg Int. 2006;22(4):326-9. https://doi. org/10.1007/s00383-006-1653-4

PMid: 16518597 